Osch, M. van, Sep, M., Vliet, L.M. van, Dulmen, S. van, Bensing, J.M. Reducing patients' anxiety and uncertainty, and improving recall in bad news consultations. Health Psychology: 2014, 33(11), 1382-1390

\begin{tabular}{|l|l|}
$\begin{array}{l}\text { Postprint } \\
\text { Version }\end{array}$ & 1.0 \\
\hline Journal website & http://psycnet.apa.org/psycinfo/2014-31639-001/ \\
\hline Pubmed link & $\underline{\text { http://www.ncbi.nlm.nih.gov/pubmed/25089344 }}$ \\
\hline DOI & $10.1037 /$ hea0000097
\end{tabular}

This is a NIVEL certified Post Print, more info at http://www.nivel.eu

\title{
Reducing patients’ anxiety and uncertainty, and improving recall in bad news consultations.
}

Mara VAN OsCh, MSC ${ }^{1}$, Milou SeP, BSc ${ }^{1}$, Liesbeth M. VAN VLIET, PhD ${ }^{1}$, SANDRA VAN Dulmen, PhD, Professor of COMMUNiCATION IN HEALTHCARE ${ }^{1,2,3}$, JOZIEN M. BENSING, PHD, HONORARY RESEARCH FELLOW, PROFESSOR IN HEALTH PSYCHOLOGY ${ }^{1,4}$

${ }^{1}$ NIVEL (Netherlands institute for health services research), Utrecht, The Netherlands

${ }^{2}$ Department of Primary and Community Care, Radboud University Nijmegen Medical Centre, Nijmegen, The Netherlands

${ }^{3}$ Department of Health Science, Buskerud University College, Drammen, Norway

${ }^{4}$ Department of Clinical and Health Psychology, Utrecht University, Utrecht, The Netherlands

\section{Abstract}

Objective: Patients' recall of provided information during bad news consultations is poor. According to the attentional narrowing hypothesis, the emotional arousal caused by the bad news might be responsible for this hampered information processing. Because affective communication has proven to be effective in tempering patients' emotional reactions, the current study aims to explore in an experimental design whether physician's affective communication in bad news consultations decreases patients' anxiety and uncertainty and improves information recall.

Methods: Two scripted video-vignettes of a bad news consultation were used in which physician's verbal communication was manipulated (standard vs. affective condition). Fifty healthy women (i.e. analogue patients) randomly watched one of the two videos. The effect of communication on participants' anxiety, uncertainty, and recall was assessed by self-report questionnaires. Additionally, a moderator analysis was performed.

Results: Affective communication reduced anxiety $(\mathrm{p}=.01$ ) and uncertainty ( $\mathrm{p}$ $=.04)$, and improved recall $(\mathrm{p}=.05)$, especially for information about prognosis $(p=.04)$ and to some extent for treatment options $(p=.07)$. The moderating effect of (reduced) anxiety and uncertainty on recall could not be confirmed and showed a trend for uncertainty.

Conclusions: Physicians' affective communication can temper patients' anxiety and uncertainty during bad news consultations, and enhance their ability to 
Osch, M. van, Sep, M., Vliet, L.M. van, Dulmen, S. van, Bensing, J.M. Reducing patients' anxiety and uncertainty, and improving recall in bad news consultations. Health Psychology: 2014, 33(11), 1382-1390

recall medical information. The reduction of anxiety and uncertainty could not explain patients' enhanced recall, which leaves the underlying mechanism unspecified. Our findings underline the importance of addressing patients' emotions and provide empirical support to incorporate this in clinical guidelines and recommendations.

\section{INTRODUCTION}

Breaking bad news - for instance, when a life-limiting cancer diagnosis is conveyed - evokes intense emotional responses in patients including anxiety and uncertainty (Harvey, Cohen, Brenin, Nicholson, \& Adams, 2007; Schofield et al., 2003). During bad news consultations patients have to deal with these emotions while they simultaneously have to focus on the medical information being provided.

Remembering medical information is crucial for patients as it is a prerequisite for coping with their disease, and making informed treatment decisions (De Haes \& Bensing, 2009; Ong, De Haes, Hoos, \& Lammes, 1995). Despite its importance, patients' information recall is overall poor: 40-80 percent of the medical information provided is forgotten immediately (Kessels, 2003). Most patients do remember their diagnosis, but have difficulty recalling information such as treatment plans, recommendations and side effects (Friis, Elverdam, \& Schmidt, 2003; Gabrijel et al., 2008; Jansen et al., 2008; Kim \& Alvi, 1999). Jansen et al. (2008) demonstrated that cancer patients remembered no more than $23 \%$ of the provided recommendations on dealing with side effects.

The instantly evoked emotional reactions may be responsible for patients' poor recall (Schwabe \& Wolf, 2010). According to the attentional narrowing hypothesis, high emotional arousal produced by an emotional event requires attention, which leaves fewer attentional resources available for peripheral information (Christianson, 1992; Kessels, 2003). Consequently, information related to the source of arousal, i.e. core information, is better remembered than the peripheral information which surrounds the emotional event, i.e. additional information. Additional information might thus not be processed (correctly) into memory (Schwabe \& Wolf, 2010). Regarding bad news consultations, diagnostic and prognostic information might be better remembered than, for example, information about treatment-options or side effects. To enhance patients' information recall, addressing emotions by means of affective communication might be the crux. Extensive research has shown that physicians' affective communication (i.e. being emotionally supportive; adopting in a warm, empathic, and reassuring manner) may bring about beneficial patients' outcomes, such as reduced levels of anxiety and distress (Di Blasi, Harkness, Ernst, Georgiou, \& Kleijnen, 2001; DiMatteo, 2004; Epstein \& Street, 2007; Rodin et al., 2009; Schmid Mast, Kindlimann, \& Langewitz, 2005; Stewart, 1995; Street, Makoul, Neeraj, \& and Epstein, 2009; Van Dulmen \& Bensing, 2002; Venetis, Robinson, Turkiewicz, \& Allen, 2009). Moreover, Jansen et al. (2010) showed that when nurses responded with minimal encouragements to patients' emotional cues, patients recalled more information. To this end, a recent study by our research group demonstrated that affective communication indeed enhances (analogue) patients' information recall (Sep, Van Osch, Van Vliet, Smets, \& Bensing, submitted for publication). 
Osch, M. van, Sep, M., Vliet, L.M. van, Dulmen, S. van, Bensing, J.M. Reducing patients' anxiety and uncertainty, and improving recall in bad news consultations. Health Psychology: 2014, 33(11), 1382-1390

The effect of affective communication on recall, however, should be further established since evidence is lacking especially for bad news consultations. Due to ethical constraints, most clinical studies rely on retrospective or cross-correlation research designs (Street, 2003; Suchman, 2006) that provide no insight into the specific mechanisms by which health care providers can influence patients' health. Although a few experimental studies found no relationship between affective communication and patients' recall (Aruguete \& Roberts, 2000; Bradley, Sparks, \& Nesdale, 2001; Fogarty, Curbow, Wingard, McDonnell, \& Somerfield, 1999), others found that the lack of affective communication deteriorates recall (Jansen et al., 2010; Shapiro, Boggs, Melamed, \& Graham-Pole, 1992). Additionally, the assessment of recall varies across studies. Most studies tend to assess recall in a restricted way, i.e. without considering the nuance of how information is processed into memory. Questions may be directed at the recognition (by multiple-choice questions) or reproduction of information (open-ended questions), which differ largely in cognitive demand and thus memory associations (Martinez, 1999; Postman \& Jenkins, 1948). Using various question formats to vary cognitive load may offer additional insight into patients' information and memory processing. In short, to examine the effect of physicians' affective communication on patients' recall during bad news consultations, this study aims to investigate in an experimental design whether physician's affective communication style has beneficial effects on 1. patients' self-reported anxiety and uncertainty, 2. information recall, and 3. the relation between anxiety, uncertainty, and recall. Based on the literature, it is expected that physician's affective communication reduces patients' anxiety and uncertainty (hypothesis 1 ) and improves recall (hypothesis 2). The provided information was divided into core and additional information. Information regarding the diagnosis and prognosis is considered core information, as this is the central message in a bad news consultation (Baile, Buckman, Lenzi, Glober, Beale \& Kudelka, 2000; Girgis \& Sanson-Fisher, 1995) expected to elicit the most severe emotions. All the information following the bad news (i.e. information about treatment options, discussing their implications for patients and other, contextual remarks) relates to additional information. It is expected that recall for core information is independent of the level of affective communication, while additional information is dependent of the level of affective communication. Last, by performing a moderator-analysis the assumption is tested that when patients' emotional state is tempered, their ability to recall information improves (hypothesis $3)$.

\section{Methods}

\section{Experimental design}

This study has an experimental design using two versions of a role-played, scripted video-vignette with randomised allocation of participants to a standard vs. affective condition. Allocation was based on alternately order of entry. Two videos were created, depicting a male physician discussing the transition from curative to palliative breast cancer care with a female patient. Both videos were identical in the amount and content of information, but only differed in physician's affective communication (see Table 1). The videos started with a priming scene in which the video-patient introduced herself and her feelings towards the consultation, aimed to increase viewers' empathic involvement. Subsequently, the physician conveyed 
Osch, M. van, Sep, M., Vliet, L.M. van, Dulmen, S. van, Bensing, J.M. Reducing patients' anxiety and uncertainty, and improving recall in bad news consultations. Health Psychology: 2014, 33(11), 1382-1390

information about the diagnosis, prognosis, treatment options and related technical details, the implications of the treatment for the patient, and made some contextual remarks. The verbal affect manipulation appeared after the disclosure of the diagnosis and prognosis (affective condition only). The standard video took 579 seconds, the affective video 617 seconds.

A detailed description of the process of creating and validating video-vignettes has been described elsewhere (Van Vliet, Hillen, van der Wall, Plum, \& Bensing, 2013a). An extra scene was created for this particular study that discussed treatment in more detail. An oncologist and a communication expert approved the validity of this scene.

\section{Participants}

A total of 50 women between 18-65 years with no history of cancer were recruited through information leaflets in supermarkets and snowballing (participating women were not involved in snowballing). Participants took part as analogue patients (APs). This means that they were asked to watch and judge the video, while identifying with the video-patient. More specifically, they were instructed: "you will be watching a bad news consultation. When you watch the video, place yourself in the position of the video-patient, and try to imagine how you would feel if you were having this consultation.

After the video, you will receive some questions about this consultation”. APs have been used in several studies revealing representative measures of clinical patients' outcomes (Mast, Hall, Klöckner, \& Choi, 2008; Roter, Hall, \& Katz, 1987). A recent systematic review (Van Vliet et al., 2012) and empirical study (Blanch-Hartigan, Hall, Krupat, \& Irish, 2013) concluded that APs are valid proxies of clinical patients in medical communication research. To avoid confounding gender effects and to increase the likelihood of emotional involvement, only women were included. An a priori power calculation was performed as we aimed to detect differences in recall of $25 \%$ of total recalled items, expecting a standard deviation of $33 \%$ in recalled items with a power of 0.80 . A sample size of 46 would attain $80 \%$ power for determining a main effect at $\alpha=0.05$ (one-tailed).

\section{Measurements}

Background characteristics. Upon registration, participants' background characteristics were assessed: Age, nationality, education, occupation, marital status, whether participants had experience with loved ones receiving a life-limiting cancer diagnosis (i.e. 'similar experience', 1-item, yes/no), and self-rated medical knowledge about cancer ("To what extent are you familiar with medical terms about cancer and its treatment (e.g. by your profession or experience)?” 1-item, range 1: not at all, -5 : very well).

Anxiety and uncertainty. After video-watching, self-reported anxiety and uncertainty were measured by 2 items on a visual analogue scale (VAS) ("To what extent did physician's manner of communication make you feel anxious/uncertain about the future?” range: 0 - 'not anxious/uncertain at all', to 100 - 'very anxious/uncertain'). Information recall. Recall was measured by a questionnaire comparable to the questionnaire used in the study by Jansen et al. (2008). The questionnaire consisted 
Osch, M. van, Sep, M., Vliet, L.M. van, Dulmen, S. van, Bensing, J.M. Reducing patients' anxiety and uncertainty, and improving recall in bad news consultations. Health Psychology: 2014, 33(11), 1382-1390

of 23 recall items based on the content of information given by the physician. The information was divided into core information and additional information, with five subdomains (see Appendix). Information regarding 1. Diagnosis (3 items) and 2. Prognosis (2 items) was considered core information. Additional information consisted of information about 3. Treatment options and related technical details (7 items), 4. Implications of the treatment for the patient (6 items), and 5. Contextual details (5 items, e.g. "Did the doctor mention your name when he greeted you?"). Recall was assessed by a mixture of questions. Open-ended questions and completion items assessed information reproduction, i.e. active recall. Multiplechoice (MC) items measured information recognition, i.e. primed recall. MC and completion items included the response options 'I do not remember' and 'This is not mentioned by the doctor'. These response options lowered the chance of guessing correctly. MC items consisted of 5 fixed response options, and completion items of 3 response options (i.e. 2 fixed boxes and an open text field). The recall questionnaire was pilot-tested and checked for ceiling effects and adequate variation of questions. All responses were coded and scored as follows: correctly recalled (2 points), partly recalled ( 1 point), or not recalled ( 0 points, including both responses 'I do not remember' and inaccurate recall). Two coders (MO and MS) who were blind to participants' condition coded all responses. A third coder (LV) coded and scored participants' responses on 5 recall-items. Interrater reliability was satisfactory (к: 0.85 , range $0.25-1$ ). The percentage correct recall was computed using the following formula: (individual score/maximum possible score) X 100.

Manipulation check and perceived realism. The success of the manipulation was assessed by three items of an adapted version of the QUOTE-COM (as used by Van Vliet, Van der Wall, Plum, \& Bensing, 2013b). Participants rated physician’s performance on three aspects of affective communication (i.e. non-abandonment by the physician, empathy, and reassurance of support by the medical team) on a 4-point Likert scale (e.g. “The doctor showed empathy”, $1=$ not, $2=$ really not, $3=$ really yes to $4=$ yes). Perceived realism was measured on a 1-10 rating scale (i.e. "Please indicate how realistic the video was in your opinion”).

\section{Procedure}

The study was approved by the Medical Ethical Committee of Utrecht University. Upon registration, participants completed the background characteristics questionnaire and were randomised to watch one out of the two videos. At entry, participants gave informed consent but remained blind to the specific study aims. After the video, the recall, anxiety/uncertainty and manipulation check questions were completed. Last, participants were debriefed and received a voucher of $€ 20$. The total experiment lasted around one hour.

\section{Data analysis}

All data analyses were performed using STATA, 12.0. First, Fisher's exact tests and independent samples $t$-tests were used to assess differences in background characteristics between conditions, (if so, these were controlled for in the subsequent analyses), to perform the manipulation check and to check the perceived realism. 
Osch, M. van, Sep, M., Vliet, L.M. van, Dulmen, S. van, Bensing, J.M. Reducing patients' anxiety and uncertainty, and improving recall in bad news consultations. Health Psychology: 2014, 33(11), 1382-1390

Second, to test our first and second hypothesis, independent samples $t$-tests were used to compare anxiety and uncertainty, and linear regression analyses tested recall between conditions (both one-sided, $p<.05$ ). Last, multiple regression analyses were performed to test our third hypothesis to determine whether anxiety and uncertainty moderate the effect of physician's affective communication on recall. To prevent multicollinearity during multiple regression analysis, anxiety and uncertainty scores were centered (Miles \& Shevlin, 2001). The interaction term was plotted to provide insight into the direction of the slopes.

Missing data. Some data were missing for anxiety and uncertainty due to inadequate completion of questionnaires ( $N=7$, no differences between groups $p>.05$ ). These were not replaced as both were important and sensitive outcome measures in our study. All participants were included in the analyses.

\section{RESULTS}

\section{Background characteristics}

Fifty women participated. Table 2 summarises participants' background characteristics. Groups were comparable except for medical knowledge ( $p=.05$ ), for which we controlled in the subsequent analyses.

\section{Manipulation check}

In the affective condition the oncologist was perceived as providing more reassurance about non-abandonment $(p=.013)$ and support by the medical team $(p=$ $.001)$, and tended to be perceived as being more empathic $(p=.079)$, as compared to the standard condition. Both videos were seen as equally realistic (Standard condition: $M=6.88, S D=1.62$; Affective condition: $M=7.36, S D=1.52, p=.29$ ).

\section{Anxiety and uncertainty}

Women reported feeling less anxious following the affective condition than the standard condition (Affective condition: $M=57.36, S D=28.39$; Standard condition: $M=73.81, S D=16.82, t(41)=2.30, p=.013)$. Furthermore, less uncertainty was reported following the affective condition than the standard condition (Affective condition: $M=53.09, S D=27.53$; Standard condition: $M=66.19, S D=21.12 ; t(42)$ $=1.76, p=.043)$.

\section{Information recall}

Table 3 displays the percentage of correct recall per condition, controlled for medical knowledge. Over the entire consultation, less information was recalled in the standard condition (49\%) as compared to the affective condition (56\%), $p=.047$. Both groups showed accurate recall for core information: 82 to $87 \%$ of diagnostic information and 80 to $86 \%$ of the prognostic information in the standard and affective condition, respectively. Recalling diagnostic information was not influenced by affective communication, whereas recall of prognosis was significantly higher for the affective condition, $p=.038$.

When additional information was discussed, recall was lower for both groups. However, participants who watched the affective video tended to recall more 
Osch, M. van, Sep, M., Vliet, L.M. van, Dulmen, S. van, Bensing, J.M. Reducing patients' anxiety and uncertainty, and improving recall in bad news consultations. Health Psychology: 2014, 33(11), 1382-1390

information about the treatment options, $p=.072$, and contextual details, $p=.092$. Physician's communication style had no influence on recalling information about patients' implications.

Table 4 presents the mean percentages for primed and active recall adjusted for medical knowledge. Only some differences were observed between primed and active recall. In general, primed recall was higher than active recall with no differences between conditions. Remarkably, the affective condition had higher primed recall for contextual details in comparison with the standard condition (70 versus $43 \% ; p=.032$ ), and also showed more active recall for prognostic information (72 versus $60 \%$ respectively, $p=.038$ ).

\section{Relationship between anxiety and uncertainty, and recall.}

Multiple regression analyses were performed to investigate the moderating effect of anxiety and uncertainty on recall. Both anxiety as uncertainty did not moderate the relationship between affective communication and recall (Anxiety: $R^{2 \Delta}=0.02$, $F(1,39)=0.91, p=.345$; Uncertainty: $R^{2 \Delta}=0.04,(F(1,40)=2,15, p=.150)$. Exploration of the slopes indicated that higher levels of uncertainty tended to lower recall in the standard condition $(B=-5.92, p=.066)$, but not for the affective condition $(B=0.23, p=.92$, see Figure 1$)$.

\section{DISCUSSION}

This study examined the effect of physicians' communication style in bad news consultations on (analogue) patients' anxiety and uncertainty, and recall of medical information. Our findings show that physician's affective communication reduces feelings of anxiety and uncertainty after receiving bad news. Moreover, affective communication enhanced the ability to recall information. The expected interaction between anxiety and uncertainty on recall could however not be confirmed.

\section{The effect of affective communication on anxiety and uncertainty.}

Our findings revealed that physician's affective communication can reduce anxiety and uncertainty. This was in line with our expectation based on both experimental (Fogarty et al., 1999; Schmid Mast et al., 2005; Shapiro et al., 1992) and clinical studies (Di Blasi et al., 2001; Ong et al., 1995; Stewart, 1995; Venetis et al., 2009). Placed in the broader context of medical encounters, our results re-emphasize the power of affective communication. A few verbal affective remarks can already be effective and this is not necessarily time consuming: It took only 38 seconds to make a difference. The affective statements that caused this reduction were related to emphasizing non-abandonment and providing reassurance of medical support. These remarks are defined as fundamental for effective patient-provider communication (Quill \& Cassel, 1995; Street et al., 2009). Whilst one of the most difficult tasks for physicians is to convey bad news (Baile, Lenzi, Parker, Buckman, \& Cohen, 2002), providers who are emotionally supportive can influence patients' emotional functioning with little effort and time.

Remarkably, though, the affective video was only perceived as somewhat more empathic than the standard video. An explanation could be that in both videos, the physician was to the same extent verbally and non-verbally empathic. The 
Osch, M. van, Sep, M., Vliet, L.M. van, Dulmen, S. van, Bensing, J.M. Reducing patients' anxiety and uncertainty, and improving recall in bad news consultations. Health Psychology: 2014, 33(11), 1382-1390

physician made adequate eye-contact; he conducted the conversation in a calm and friendly manner, and showed in both videos understanding towards patients feelings (i.e. "I’m very sorry for you"). The difference between the videos was solely these four affective statements.

\section{The effect of affective communication on recall.}

Physicians' affective communication not only tempers emotional arousal, but also enhances recall of medical information. Physician's affective statements increased recall, especially for prognostic information and to some extent for treatment information. This has promising implications for clinical practice. Our findings revealed that both groups remembered core information most accurately (i.e. diagnosis and prognosis) while having more difficulty recalling additional information. This is consistent with clinical evidence (Friis, Elverdam, \& Schmidt, 2003; Gabrijel et al., 2008; Jansen et al., 2008; Kim \& Alvi, 1999) and can be explained by attentional narrowing: the emotion evoking bad news becomes the primary focus, hampering recall for subsequently provided information. All additional information is not processed and stored into memory and therefore cannot be recalled (Christianson, 1992; Kessels, 2003; Schwabe \& Wolf, 2010). Evidence suggests that memory processes are indeed susceptible for interfering factors as emotional arousal, which impacts information processing and memory consolidation (Buchanan \& Tranel, 2008; Craik, Naveh-Benjamin, Ishaik, \& Anderson, 2000; Schwabe \& Wolf, 2010; Schwabe, Wolf, \& Oitzl, 2010).

Other explanations may be found in primacy effects and perceived importance of medical information (Kessels, 2003). Patients might remember their diagnosis and prognosis better because this information was first presented, without having preceding emotions influencing their retaining ability. Besides, information related to the bad news is perceived as profoundly important. The disclosure of the bad news message typically occurs at the beginning of the consultation (Baile et al., 2000; Girgis \& Sanson-Fisher, 1995). It might be worthwhile to investigate whether forthcoming information should be discussed at a different moment in the consultation, or even in a subsequent consultation, in an attempt to improve patients' recall. Physicians must take account of the distressing nature of the information to be given, and be responsive to patients' emotions during bad news consultations. The a priori expectation of affective communication increasing recall for additional information was not strongly confirmed. Treatment options only tended to be recalled more by affective communication. However, with respect to attentional narrowing, two interesting results were noticed in the distinction between primed and active recall. Since we have not varied types of memory between groups, and therefore both content and question format could account for variance in recall, our findings need to be interpreted with caution. First, primed recall for contextual details was almost twice as high for the affective condition as the standard condition. This implies that physician's affective remarks contributed to better information recognition from memory and more attention was, or could be, devoted to contextual components. Second, the affective condition could also actively reproduce prognostic information better, even though the manipulation of physician's affect appeared after the discussion of prognosis. Active recall relies on more complex information processing relating to the process of memory consolidation and retrieval (Martinez, 1999; Postman \& Jenkins, 1948). 
Osch, M. van, Sep, M., Vliet, L.M. van, Dulmen, S. van, Bensing, J.M. Reducing patients' anxiety and uncertainty, and improving recall in bad news consultations. Health Psychology: 2014, 33(11), 1382-1390

Both the enhanced primed recall for contextual details, as the retrospectively increased (active) recall for prognostic information may imply that affective communication facilitates information processing and, subsequently, recall as patients could direct better their attention to the information provided. Recent research has showed that positive affect expands the breadth of information processing, with more attention available for other information sources (Rowe, Hirsh, \& Anderson, 2007). It remains therefore conceivable that lowering patients' arousal by means of affective communication could alter patients' information processing abilities and consolidation into memory (for a detailed overview see the Atkinson-Shiffrin memory model, Atkinson \& Shiffrin, 1968).

\section{Relation between anxiety, uncertainty, and recall.}

Whilst physician's affective communication has an effect on recall, the proposed moderating effect of anxiety and uncertainty could not be established. However, our findings revealed an interesting trend: Higher levels of uncertainty lowered recall, but only when affective statements were lacking. More research is needed to provide evidence for the relationship between affective communication, emotional arousal and recall. Our study had a limited sample size and thus power; a larger sample may be able to corroborate this trend. Although we were unable to explain the underlying mechanism, it might be that if feelings of uncertainty are not sufficiently reduced, this can cause problems in recalling information.

\section{Medical knowledge and recall}

Participants in our study rated their self-perceived medical knowledge about cancer and its related treatment as sufficient. Although it was one item and not checked on validity, more medical knowledge seemed to facilitate recall. Possibly, medical knowledge shares similarities with health literacy, i.e. individuals' capacity to obtain, process, and understand basic health information and services needed to make appropriate health decisions. A recent study demonstrated that people with lower health literacy have poorer ability to recall information (McCarthy et al., 2012). Future research may want take account of medical knowledge and health literacy when addressing recall in enhancing the effectiveness of providers' communication in medical care.

\section{Strengths, limitations and future directions.}

The key strength of this study is its experimental design allowing us to 1 . manipulate physician's communication, 2. explore its specific effects, and 3. determine causality. What on the one hand is its strength might on the other hand be its limitation. Although recent studies demonstrated that using APs is a valid methodology (Blanch-Hartigan et al., 2013; Van Vliet et al., 2012), we cannot ignore the fact that our sample exists of healthy, highly-educated woman participating in a hypothetical situation, lowering the ecological validity. Higher educational levels are associated with better recall (Selic, Svab, Repolusk, \& Gucek, 2011) and in general, women perform better on memory tests than men (Buchanan \& Tranel, 2008). Our results might thus give an underestimation of the existing problem in health care as lower educated women (and men) may recall less. Besides, patients' emotional responses in real bad news consultations are probably even stronger, thereby affecting recall more 
Osch, M. van, Sep, M., Vliet, L.M. van, Dulmen, S. van, Bensing, J.M. Reducing patients' anxiety and uncertainty, and improving recall in bad news consultations. Health Psychology: 2014, 33(11), 1382-1390

severely. This only underlines the importance of using affective communication. The lack of cultural diversity also hampers the ecological validity. Cultural variations are acknowledged to influence medical communication (Schouten \& Meeuwesen, 2006), and the disclosure of medical information differs among cultures (Baile et al., 2002). Another limitation concerns the lack of women's baseline measured anxiety. We could not ensure whether pre-measured anxiety was comparable between groups. Future studies may want to include a baseline measure to control for potential differences. Finally, we used a quasi-randomised approach, which made it crucial to check whether groups were comparable for baseline characteristics, and to control for potential differences (i.e. medical knowledge). As a consequence of this approach, we cannot guarantee adequate concealment. We consider it unlikely, though, that this have produced any performance bias, as the experiment was conducted in accordance to the protocol and highly standardized.

Our findings empirically support existing protocols and guidelines on how to deliver bad news. It underlines the importance of affective communication, which is especially challenging during bad news conversations (Baile et al., 2002). Since conveying bad news requires specific communication skills, teaching those skills can support physicians and enhance such consultations (Back, Arnold, Baile, FryerEdwards, Alexander, Barley et al., 2007). Yet, our findings are not exclusively relevant for physicians facing the task of breaking bad news to their patients, but also for other health care providers. Affective communication may have the power to elicit beneficial effects in clinical encounters as it enables patients to adjust better to the emotional and cognitive impact of medical information (Street et al., 2009). Indirect effects might also be present. When patients remember more about treatment procedures and their consequences, this may affect adherence to treatment or medication regimen (De Haes \& Bensing, 2009; DiMatteo, 2004; Neumann et al., 2007; Street et al., 2009).

\section{Conclusion.}

In conclusion, this study indicated that a few affective statements can already have a large impact on patients' anxiety, uncertainty and recall. Affective communication allow physicians to temper patients' emotional responses and improve their ability to remember medical information. Our findings are not exclusively relevant for (palliative) cancer care, but can also apply to other medical encounters.

\section{REFERENCES}

Aruguete, M. S. \& Roberts, C. A. (2000). Gender, Affiliation, and Control in Physician-Patient Encounters. Sex Roles, 42, 107-118.

Aruguete, M. S. \& Roberts, C. A. (2002). Participants' ratings of male physicians who vary in race and communication style. Psychological Reports, 91, 793-806.

Atkinson, R. C. \& Shiffrin, R. M. (1968). Human memory: A proposed system and its control processes. In K.Spence (Ed.), The psychology of learning and motivation: Advances in research and theory (Vol. 2) (pp. 90-197). New York: Academic Press.

Back, A. L., Arnold, R. M., Baile, W. F., Fryer-Edwards, K. A., Alexander, S. C., Barley, G.

E. et al. (2007). Efficacy of communication skills training for giving bad news and discussing transitions to palliative care. Archives of Internal Medicine, 167(5), 453.

Baile, W. F., Buckman, R., Lenzi, R., Glober, G., Beale, E. A., \& Kudelka, A. P. (2000). 
Osch, M. van, Sep, M., Vliet, L.M. van, Dulmen, S. van, Bensing, J.M. Reducing patients' anxiety and uncertainty, and improving recall in bad news consultations. Health Psychology: 2014, 33(11), 1382-1390

SPIKES—a six-step protocol for delivering bad news: application to the patient with cancer The oncologist, 5(4), 302-311.

Baile, W. F., Lenzi, R., Parker, P. A., Buckman, R., \& Cohen, L. (2002). Oncologists' Attitudes Toward and Practices in Giving Bad News: An Exploratory Study. Journal of Clinical Oncology, 20, 2189-2196.

Blanch-Hartigan, D., Hall, J. A., Krupat, E., \& Irish, J. T. (2013). Can Naive Viewers Put Themselves in the Patients Shoes?: Reliability and Validity of the Analogue Patient Methodology. Medical Care, 51.

Bradley, G. R. A. H., Sparks, B. E. V. E., \& Nesdale, D. R. E. W. (2001). Doctor Communication Style and Patient Outcomes: Gender and Age as Moderators. Journal of Applied Social Psychology, 31, 1749-1773.

Buchanan, T. W. \& Tranel, D. (2008). Stress and emotional memory retrieval: Effects of sex and cortisol response. Neurobiology of Learning and Memory, 89, 134-141.

Christianson, S.-A. (1992). Emotional stress and eyewitness memory: A critical review. Psychological bulletin, 112, 284-309.

Craik, F. I. M., Naveh-Benjamin, M., Ishaik, G., \& Anderson, N. D. (2000). Divided Attention During Encoding and Retrieval: Differential Control Effects? Journal of Experimental Psychology: Learning, Memory, \& Cognition., 26, 1744-1749.

De Haes, H. \& Bensing, J. (2009). Endpoints in medical communication research, proposing a framework of functions and outcomes. Patient education and counseling, 74, 287-294.

Di Blasi, Z., Harkness, E., Ernst, E., Georgiou, A., \& Kleijnen, J. (2001). Influence of context effects on health outcomes: A systematic review. Lancet, 357, 757-762.

DiMatteo, M. R. (2004). Social support and patient adherence to medical treatment: a metaanalysis. Health Psychology, 23, 207.

Epstein, R. M. \& Street, R. L. (2007). Patient-centered communication in cancer care: Promoting healing and reducing suffering. National Cancer Institute, NIH Publication No. 07-6225.

Fogarty, L. A., Curbow, B. A., Wingard, J. R., McDonnell, K., \& Somerfield, M. R. (1999). Can 40 seconds of compassion reduce patient anxiety. Journal of Clinical Oncology, 17, 371-379.

Friis, L. S., Elverdam, B., \& Schmidt, K. G. (2003). The patient's perspective: A qualitative study of acute myeloid leukaemia patients' need for information and their informationseeking behaviour. Supportive Care in Cancer, 11, 162-170.

Gabrijel, S., Grize, L., Helfenstein, E., Brutsche, M., Grossman, P., Tamm, M. et al. (2008). Receiving the diagnosis of lung cancer: Patient recall of information and satisfaction with physician communication. Journal of Clinical Oncology, 26, 297-302.

Girgis, A., \& Sanson-Fisher, R. W. (1995). Breaking bad news: consensus guidelines for medical practitioners. Journal of Clinical Oncology, 13(9), 2449-2456.

Harvey, J. A., Cohen, M. A., Brenin, D. R., Nicholson, B. T., \& Adams, R. B. (2007). Breaking Bad News: A Primer for Radiologists in Breast Imaging. Journal of the American College of Radiology, 4, 800-808.

Jansen, J., Van Weert, J., Van Der Meulen, N., Van Dulmen, S., Heeren, T., \& Bensing, J. (2008). Recall in older cancer patients: Measuring memory for medical information. Gerontologist, 48, 149-157.

Jansen, J., van Weert, J. C. M., de Groot, J., van Dulmen, S., Heeren, T. J., \& Bensing, J. M. (2010). Emotional and informational patient cues: The impact of nurses responses on recall. Patient Education and Counseling, 79, 218-224.

Kessels, R. P. C. (2003). Patients' memory for medical information. Journal of the Royal Society of Medicine, 96, 219-222.

Kim, M. K. \& Alvi, A. (1999). Breaking the bad news of cancer: The patient's perspective. Laryngoscope, 109, 1064-1067.

Lelorain, S., Brédart, A., Dolbeault, S., \& Sultan, S. (2012). A systematic review of the associations between empathy measures and patient outcomes in cancer care. Psychooncology, n/a.

Martinez, M. E. (1999). Cognition and the question of test item format. Educational Psychologist, 34, 207-218.

Mast, M. S., Hall, J. A., Klöckner, C., \& Choi, E. (2008). Physician Gender Affects How Physician Nonverbal Behavior Is Related to Patient Satisfaction. Medical Care, 46. 
Osch, M. van, Sep, M., Vliet, L.M. van, Dulmen, S. van, Bensing, J.M. Reducing patients' anxiety and uncertainty, and improving recall in bad news consultations. Health Psychology: 2014, 33(11), 1382-1390

McCarthy, D. M. M., Waite, K. R. B., Curtis, L. M. M., Engel, K. G. M., Baker, D. W. M., \& Wolf, M. S. P. M. (2012). What Did the Doctor Say? Health Literacy and Recall of Medical Instructions. [Article]. Medical care, 50, 277-282.

Miles, J. \& Shevlin, M. (2001). Applying regression and correlation: A guide for students and researchers. SAGE Publications Limited.

Neumann, M., Wirtz, M., Bollschweiler, E., Mercer, S. W., Warm, M., Wolf, J. et al. (2007). Determinants and patient-reported long-term outcomes of physician empathy in oncology: A structural equation modelling approach. Patient education and counseling, 69, 63-75.

Ong, L. M. L., De Haes, J. C. J. M., Hoos, A. M., \& Lammes, F. B. (1995). Doctor-patient communication: A review of the literature. Social Science and Medicine, 40, 903-918.

Postman, L. \& Jenkins, W. O. (1948). An experimental analysis of set in rote learning: the interaction of learning instruction and retention performance. Journal of experimental psychology, 38, 683-689.

Quill, T. E. \& Cassel, C. K. (1995). Nonabandonment: A Central Obligation for Physicians. Annals of Internal Medicine, 122, 368-374.

Rodin, G., MacKay, J. A., Zimmermann, C., Mayer, C., Howell, D., Katz, M. et al. (2009). Clinician-patient communication: A systematic review. Supportive Care in Cancer, 17, 627644.

Roter, D. L., Hall, J. A., \& Katz, N. R. (1987). Relations between physicians' behaviors and analogue patients' satisfaction, recall, and impressions. Medical care, 25, 437-451.

Rowe, G., Hirsh, J. B., \& Anderson, A. K. (2007). Positive affect increases the breadth of attentional selection. Proceedings of the National Academy of Sciences, 104, 383-388.

Schmid Mast, W., Kindlimann, A., \& Langewitz, W. (2005). Recipients' perspective on breaking bad news: how you put it really makes a difference. Patient education and counseling, 58, 244-251.

Schofield, P. E., Butow, P. N., Thompson, J. F., Tattersall, M. H. N., Beeney, L. J., \& Dunn, S. M. (2003). Psychological responses of patients receiving a diagnosis of cancer. Annals of Oncology, 14, 48-56.

Schouten, B. C., \& Meeuwesen, L. (2006). Cultural differences in medical communication: a review of the literature. Patient education and counseling, 64(1), 21-34.

Schwabe, L. \& Wolf, O. T. (2010). Learning under stress impairs memory formation. Neurobiology of Learning and Memory, 93, 183-188.

Schwabe, L., Wolf, O. T., \& Oitzl, M. S. (2010). Memory formation under stress: Quantity and quality. Neuroscience \& Biobehavioral Reviews, 34, 584-591.

Selic, P., Svab, I., Repolusk, M., \& Gucek, N. (2011). What factors affect patients' recall of general practitioners' advice? BMC Family Practice, 12, 141.

Sep, M., Van Osch, M., Van Vliet, L. M., Smets, E. M. A., \& Bensing, J. M (2014). The power of clinicians' affective communication: How reassurance about non-abandonment can reduce patients' physiological arousal and increase information recall in bad news consultations. An experimental study using analogue patients. Patient education and counseling, in press.

Shapiro, D. E., Boggs, S. R., Melamed, B. G., \& Graham-Pole, J. (1992). The effect of varied physician affect on recall, anxiety, and perceptions in women at risk for breast cancer: an analogue study. Health Psychology, 11, 61-66.

Stewart, M. A. (1995). Effective physician-patient communication and health outcomes: A review. Canadian Medical Association Journal, 152, 1423-1433.

Street, R. L. (2003). Communication in medical encounters: an ecological perspective. In A.M.Dorsey, K. I. Miller, R. Parrott, \& T. L. and Thompson (Eds.), Handbook of health communication (pp. 63-94). New York: Lawrence Earlbaum.

Street, R. L. J., Makoul, G., Neeraj, K. A., \& and Epstein, R. M. (2009). How does communication heal? Pathways linking clinician-patient communication to health outcomes. Patient education and counseling, 74, 295-301.

Suchman, A. L. (2006). A new theoretical foundation for relationship-centered care: Complex responsive processes of relating. Journal of General Internal Medicine, 21, S40-S44.

Van Dulmen, A. M. \& Bensing, J. M. (2002). Health promoting effects of the physicianpatient encounter. Psychology, Health \& Medicine, 7, 289-300.

Van Vliet, L., Wall, E., Albada, A., Spreeuwenberg, P., Verheul, W., \& Bensing, J. (2012). The Validity of Using Analogue Patients in Practitioner-Patient Communication Research: 
Osch, M. van, Sep, M., Vliet, L.M. van, Dulmen, S. van, Bensing, J.M. Reducing patients' anxiety and uncertainty, and improving recall in bad news consultations. Health Psychology: 2014, 33(11), 1382-1390

Systematic Review and Meta-Analysis. Journal of General Internal Medicine, 27, 15281543.

Van Vliet, L. M., Hillen, M. A., van der Wall, E., Plum, N., \& Bensing, J. M. (2013a). How to create and administer scripted video-vignettes in an experimental study on disclosure of a palliative breast cancer diagnosis. Patient education and counseling, 91(1), 56-64.

Van Vliet, L. M., van der Wall, E., Plum, N. M., \& Bensing, J. M. (2013b). Explicit Prognostic Information and Reassurance About Nonabandonment When Entering Palliative Breast Cancer Care: Findings From a Scripted Video-Vignette Study. Journal of Clinical Oncology.

Venetis, M. K., Robinson, J. D., Turkiewicz, K. L., \& Allen, M. (2009). An evidence base for patient-centered cancer care: A meta-analysis of studies of observed communication between cancer specialists and their patients. Patient education and counseling, 77, 379383. 
Osch, M. van, Sep, M., Vliet, L.M. van, Dulmen, S. van, Bensing, J.M. Reducing patients' anxiety and uncertainty, and improving recall in bad news consultations. Health Psychology: 2014, 33(11), 1382-1390

\section{APPENDIX (ONLINE SUPPLEMENT)}

Detailed overview of the various recall items for each information domain, distinguished into core and additional information in accordance to the attentional narrowing hypothesis.

\begin{tabular}{|c|c|c|c|}
\hline Category & $\begin{array}{l}\text { Information } \\
\text { domain }\end{array}$ & Item & $\begin{array}{l}\text { Question } \\
\text { format }\end{array}$ \\
\hline \multirow{5}{*}{ 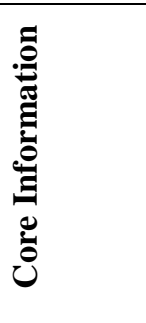 } & \multirow[t]{3}{*}{ Diagnosis } & - Did the doctor discuss with you whether you can recover? & MC \\
\hline & & - Why is it not possible to cure of cancer? & Open \\
\hline & & - Did the doctor discuss with you where the cancer metastases are located? & Completion \\
\hline & \multirow[t]{2}{*}{ Prognosis } & $\begin{array}{l}\text { - Did the doctor discuss with you your life expectancy? If so, please indicate what } \\
\text { the doctor has told you exactly. }\end{array}$ & Open \\
\hline & & $\begin{array}{l}\text { - The doctor gave specific data and average numbers about your life expectancy. } \\
\text { Could vou indicate what he has said exactly? }\end{array}$ & MC \\
\hline \multirow{18}{*}{ 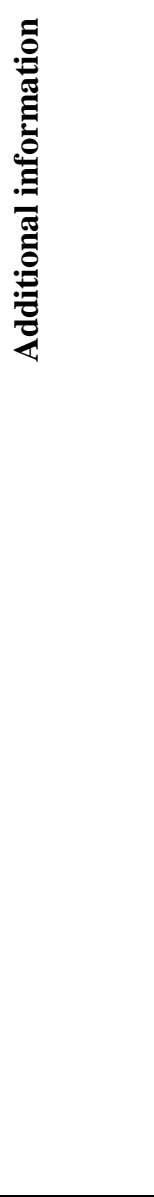 } & \multirow{7}{*}{$\begin{array}{l}\text { Treatment options } \\
\text { and related } \\
\text { technical details }\end{array}$} & $\begin{array}{l}\text { - Several treatments are discussed. Which treatment(s) is/are still possible for } \\
\text { you? }\end{array}$ & Completion \\
\hline & & - Did the doctor discuss with you the benefits of chemotherapy? & Completion \\
\hline & & $\begin{array}{l}\text { - The doctor explained how chemotherapy works. Can you indicate how that } \\
\text { happens? }\end{array}$ & MC \\
\hline & & $\begin{array}{l}\text { - The doctor discussed the importance of chemotherapy. Can you indicate what } \\
\text { the doctor has told you about the consequences of the metastases in your liver and } \\
\text { bones, if the cancer is not treated? }\end{array}$ & Completion \\
\hline & & - Did the doctor use an other word for chemotherapy? & Completion \\
\hline & & $\begin{array}{l}\text { - Chemotherapy increases the risk of infections. Has the doctor told you how this } \\
\text { happens? }\end{array}$ & Completion \\
\hline & & - How is chemotherapy administered? & MC \\
\hline & \multirow{6}{*}{$\begin{array}{l}\text { Implications of its } \\
\text { treatment for the } \\
\text { patient }\end{array}$} & - What has been decided about the start of chemotherapy? & MC \\
\hline & & - Where will the chemotherapy takes place? & MC \\
\hline & & - Did the doctor discuss the side effect(s) of chemotherapy with you? & Completion \\
\hline & & $\begin{array}{l}\text { - Does the doctor tell you in how many treatments you will get chemotherapy, if } \\
\text { so, how many? }\end{array}$ & Completion \\
\hline & & $\begin{array}{l}\text { - Did the doctor offer you to make an appointment with one of the following } \\
\text { persons if you would like to do so? }\end{array}$ & $\mathrm{MC}$ \\
\hline & & - During this consultation, has there been spoken about a second opinion? & MC \\
\hline & \multirow{5}{*}{$\begin{array}{l}\text { Contextual } \\
\text { remarks }\end{array}$} & - What was the name of the doctor you have spoken with? & Open \\
\hline & & $\begin{array}{l}\text { - What is the name of the surgeon who was responsible for the prior } \\
\text { examinations? }\end{array}$ & Open \\
\hline & & - Did the doctor mention your name when he greeted you? & $\mathrm{MC}$ \\
\hline & & - Did the doctor present himself to your husband? & MC \\
\hline & & - At one moment, the doctor gets up. Did he tell you why? & Open \\
\hline
\end{tabular}

N.B.: The various question formats refer to: $1 . \mathrm{MC}=$ Multiple-choice item, 2 . Open = Open-ended question, 3. Completion $=$ Completion item . 
Osch, M. van, Sep, M., Vliet, L.M. van, Dulmen, S. van, Bensing, J.M. Reducing patients' anxiety and uncertainty, and improving recall in bad news consultations. Health Psychology: 2014, 33(11), 1382-1390

Table 1 Manipulation segments of physician’s affective communication.

\section{Included affective remarks in video manipulation}

-“But whatever we will do, and however that develops, we will continue to take good care of you. We will be with you all the way."

-"We will do and will continue to do our very best for you."

-“Whatever happens, we will never abandon you. You are not facing this on your own.”

-“I understand your reluctance [towards chemotherapy]. Together we will have a careful look at that decision and will keep a close eye on your concerns.”

N.B.: These remarks were only included in the affective video. The standard video lacks these remarks. 
Osch, M. van, Sep, M., Vliet, L.M. van, Dulmen, S. van, Bensing, J.M. Reducing patients' anxiety and uncertainty, and improving recall in bad news consultations. Health Psychology: 2014, 33(11), 1382-1390

Table 2 Background characteristics of participants summarized per condition.

\begin{tabular}{|c|c|c|c|}
\hline \multirow[b]{2}{*}{ Variable } & \multicolumn{2}{|c|}{ Condition } & \multirow[b]{4}{*}{$(p)$} \\
\hline & Standard & Affective & \\
\hline & $\mathrm{N}=25$ & $N=25$ & \\
\hline & Mean (SD) & Mean (SD) & \\
\hline \multirow[t]{2}{*}{ Age } & $39.2(15.5)$ & $44.0(13.7)$ & $.26(t=-1.15)$ \\
\hline & $\mathrm{N}(\%)$ & $\mathrm{N}(\%)$ & \\
\hline Highest education & & & .114 \\
\hline Lower (< secondary school) & - & $1(4)$ & \\
\hline Middle (secondary school + vocational & $10(40)$ & $4(16)$ & \\
\hline education) & & & \\
\hline High (higher vocational education or & $15(60)$ & $20(80)$ & \\
\hline \multicolumn{4}{|l|}{ University) } \\
\hline Marital Status & & & $.32 \underline{3}$ \\
\hline Married (incl. registered partnership) & $4(16)$ & $8(32)$ & \\
\hline Never married & $19(76)$ & $14(56)$ & \\
\hline Other (divorced/widowed) & $2(8)$ & $3(12)$ & \\
\hline Occupation & & & .802 \\
\hline Studying & $5(20)$ & $5(20)$ & \\
\hline Paid Employment & $9(36)$ & $10(40)$ & \\
\hline Unemployed/Looking for work/Disabled & $6(24)$ & $5(20)$ & \\
\hline Housewife/Retired & $1(4)$ & $3(12)$ & \\
\hline Other & $4(16)$ & $2(8)$ & \\
\hline Country of Birth & & & - \\
\hline The Netherlands & $25(100)$ & $24(96)$ & \\
\hline Other & - & $1(1)$ & \\
\hline Similar Experience & & & .227 \\
\hline Yes & 13 (54.17) & $18(75)$ & \\
\hline No & $11(45.83)$ & $6(25)$ & \\
\hline Medical Knowledge & & & .046 \\
\hline Not at all & $3(12.5)$ & $1(4.17)$ & \\
\hline Not well & $3(12.5)$ & $1(4.17)$ & \\
\hline Moderate & 14 (58.33) & $8(33.33)$ & \\
\hline Well & $3(12.5)$ & $11(45.83)$ & \\
\hline Very well & $1(4.17)$ & $3(12.5)$ & \\
\hline
\end{tabular}

N.B.: Groups were comparable for demographics (Fisher' exact test $p>.05$ ), except for medical knowledge $(p=.046){ }^{*}=p<.05$. 
Osch, M. van, Sep, M., Vliet, L.M. van, Dulmen, S. van, Bensing, J.M. Reducing patients' anxiety and uncertainty, and improving recall in bad news consultations. Health Psychology: 2014, 33(11), 1382-1390

Table 3 Adjusted mean (percentages and SE) for information recall per condition.

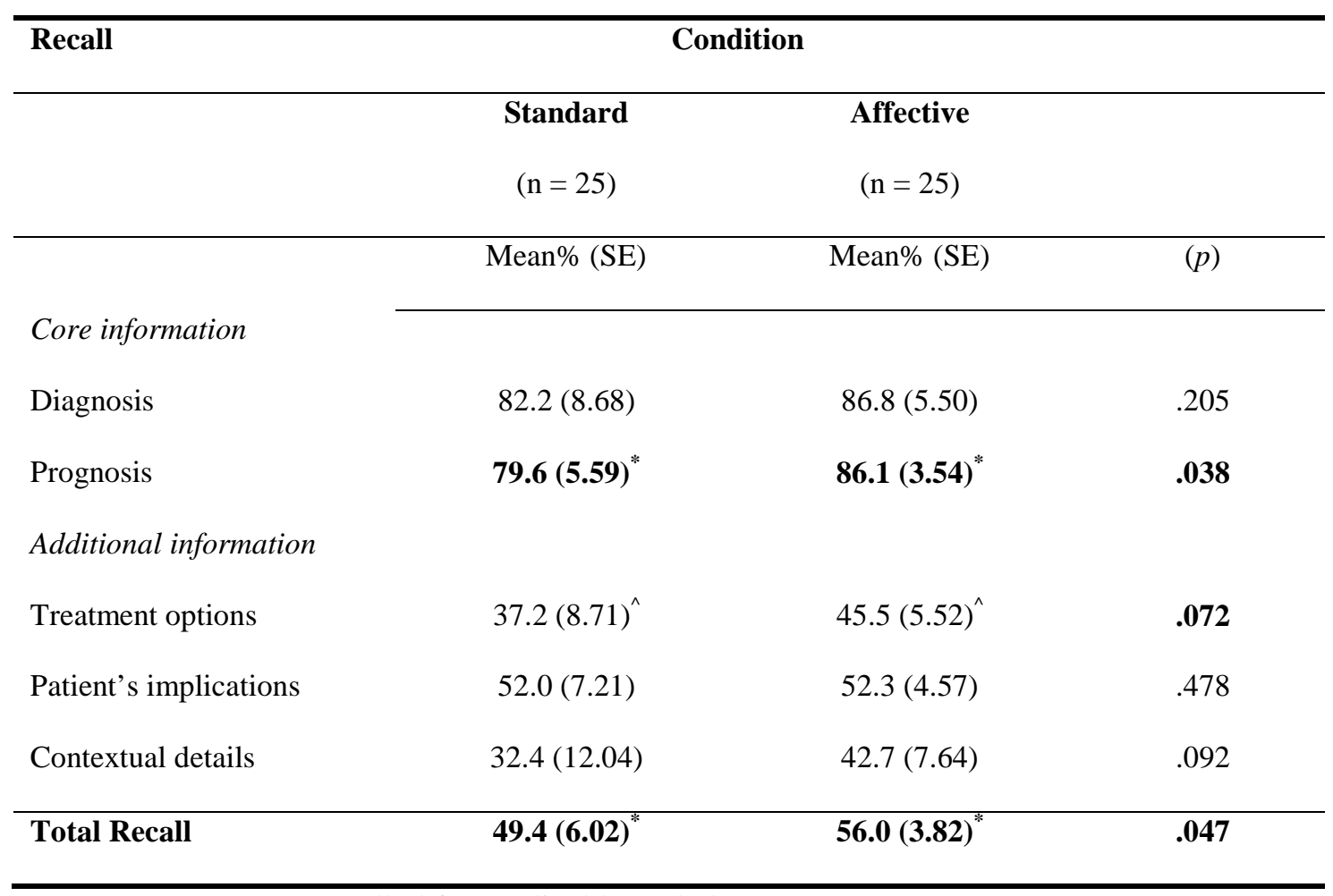

NB: outcomes are controlled for medical knowledge. ${ }^{*}=p<.05$. 
Osch, M. van, Sep, M., Vliet, L.M. van, Dulmen, S. van, Bensing, J.M. Reducing patients' anxiety and uncertainty, and improving recall in bad news consultations. Health Psychology: 2014, 33(11), 1382-1390

Table 4 Adjusted means (percentages and SE) for primed and active recall per condition.

\begin{tabular}{|c|c|c|c|c|c|c|}
\hline \multirow[t]{4}{*}{ Recall } & \multicolumn{2}{|c|}{ Primed recall (\%) } & \multicolumn{4}{|c|}{ Active recall (\%) } \\
\hline & \multicolumn{2}{|c|}{ Condition } & \multicolumn{4}{|c|}{ Condition } \\
\hline & Standard & Affective & $(p)$ & Standard & Affective & $(p)$ \\
\hline & Mean\% (SE) & Mean\% (SE) & & Mean\% (SE) & Mean\% (SE) & \\
\hline \multicolumn{7}{|l|}{ Core information } \\
\hline Diagnosis & $95.3(4.37)$ & $96.4(6.41)$ & .435 & $73.5(11.42)$ & $79.6(7.24)$ & .202 \\
\hline Prognosis & $100(-)$ & $100(-)$ & - & $59.3(11.18)^{*}$ & $72.2(7.09)^{*}$ & .038 \\
\hline \multicolumn{7}{|l|}{ Additional information } \\
\hline Treatment options & $47.1(15.78)$ & $58.6(11.48)$ & .129 & $33.3(9.57)$ & $40.2(6.07)$ & .129 \\
\hline Patient's implications & $63.4(8.57)$ & $59.8(5.43)$ & .252 & $29.2(13.56)$ & $37.3(8.07)$ & .176 \\
\hline Contextual details & $43.2(22.54)^{*}$ & 70.5 (14.29)* & .032 & $25.3(12.25)$ & $24.2(7.77)$ & .449 \\
\hline Total Recall & $63.4(7.23)$ & $69.8(4.59)$ & .083 & $39.0(6.99)$ & $44.6(4.43)$ & .106 \\
\hline
\end{tabular}

N.B. Outcomes are controlled for medical knowledge. Primed recall was measured by multiple-choice items; active recall was measured by open ended questions and completion items. $*=p<.05$. 
Osch, M. van, Sep, M., Vliet, L.M. van, Dulmen, S. van, Bensing, J.M. Reducing patients' anxiety and uncertainty, and improving recall in bad news consultations. Health Psychology: 2014, 33(11), 1382-1390

Figure 1 Interaction plot of the effect of uncertainty on the relation between physician's communication style and recall (in percentages). N.B.: Due to centering, a score below zero refers to low uncertainty, whereas a score above zero indicates higher levels of uncertainty.

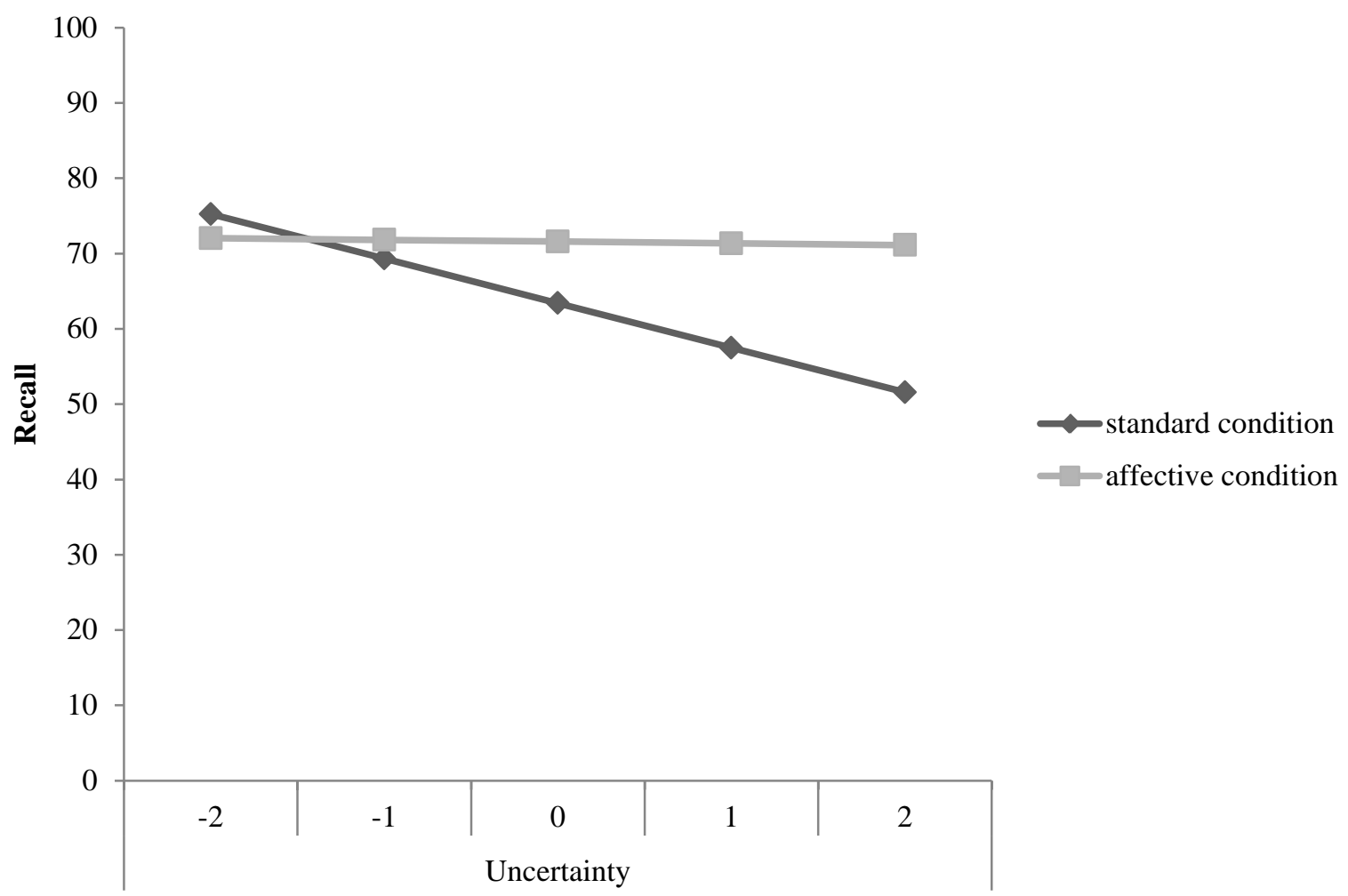

